\title{
Cold-season Tornado Risk Communication: Case Studies from November 2016 to February 2017 0
}

\author{
SAMUEL J. CHILDS AND RUSS S. SCHUMACHER \\ Department of Atmospheric Science, Colorado State University, Fort Collins, Colorado
}

(Manuscript received 11 July 2017, in final form 9 February 2018)

\begin{abstract}
Cold-season tornadoes, defined here as those occurring during November-February (NDJF), pose many societal risks. Not only do they occur when tornadoes are least common in the United States, but NDJF tornadoes also tend to be nocturnal and are most prevalent in the Southeast, where complex terrain, limited resources, and a high mobile home density add social vulnerabilities. In the period 1953-2015, within the domain of $25^{\circ}-42.5^{\circ} \mathrm{N}, 75^{\circ}-100^{\circ} \mathrm{W}$, over 900 people were killed as a result of NDJF tornadoes. Moreover, NDJF tornado frequency is increasing much faster than that of annual tornadoes. Given the enhanced societal risk, particularly in the Southeast, effective communication between professionals and the public is imperative during a cold-season tornado event. This study investigates communication strategies and barriers from the perspective of National Weather Service and broadcast meteorologists, as well as emergency managers, through a postevent survey of four major tornado events from November 2016 to February 2017. Barriers to tornado risk communication identified by the professionals included public "me-centeredness," inconsistent messages, and timing and meteorological uncertainties, as well as case-specific factors. Meteorologists perceived their communities as vulnerable to tornadoes in general, yet also prepared and receptive to warnings. Factors influencing perceived barriers and vulnerability are incorporated into a conceptual model of tornado risk communication, which is applicable to tornadoes in general. Ideas for overcoming these barriers include consolidation of warning graphics, collaboration between the meteorological and social science communities, and improved education of tornado risks for the most vulnerable sectors of society.
\end{abstract}

\section{Introduction}

Cold-season tornadoes pose many societal risks. For example, they can catch people off guard because of the relative infrequency of tornadoes during winter (Fike 1993; Simmons and Sutter 2007). People can also be unsuspecting of threatening weather during the cold season due to the bustle of family activities and holidays like Thanksgiving, Christmas, and New Year's. Coldseason tornado spatial distribution is weighted toward the southern and southeastern United States, where a variety of nonmeteorological factors increase societal risk (Childs et al. 2018). These factors include a high mobile home density, a large and increasing elderly

\footnotetext{
Supplemental information related to this paper is available at the Journals Online website: https://doi.org/10.1175/WCAS-D-170073.s1.
}

Corresponding author: Samuel J. Childs, sjchilds@rams.colostate. edu population, enhanced poverty, and forested terrain (Ashley 2007; Bergstrand et al. 2015; Ashley and Strader 2016). In fact, Emrich and Cutter (2011) used a principal component analysis of the Social Vulnerability Index (SoVI), a quantitative metric for assessing human vulnerability (Cutter et al. 2003), and found elevated levels in the lower Mississippi River Valley. This area is also a prime region for nocturnal tornadoes (Davies and Fischer 2009; Sherburn et al. 2016), and Ashley et al. (2008) report that the southeastern United States experiences almost half of its tornadoes after sunset. Surely, some of the enhancement in nocturnal counts is due to shorter days in winter, but the meteorological conditions and more progressive storm systems that impact the Southeast during winter are also factors (Sherburn et al. 2016). Nocturnal tornadoes add an additional risk of the public being unable to obtain warnings or see the ominous conditions (Paul et al. 2003), especially if they do not have adequate technology. Even beliefs in God (Sims and Baumann 1972) and the reliability (or lack thereof) of tornado warning systems 


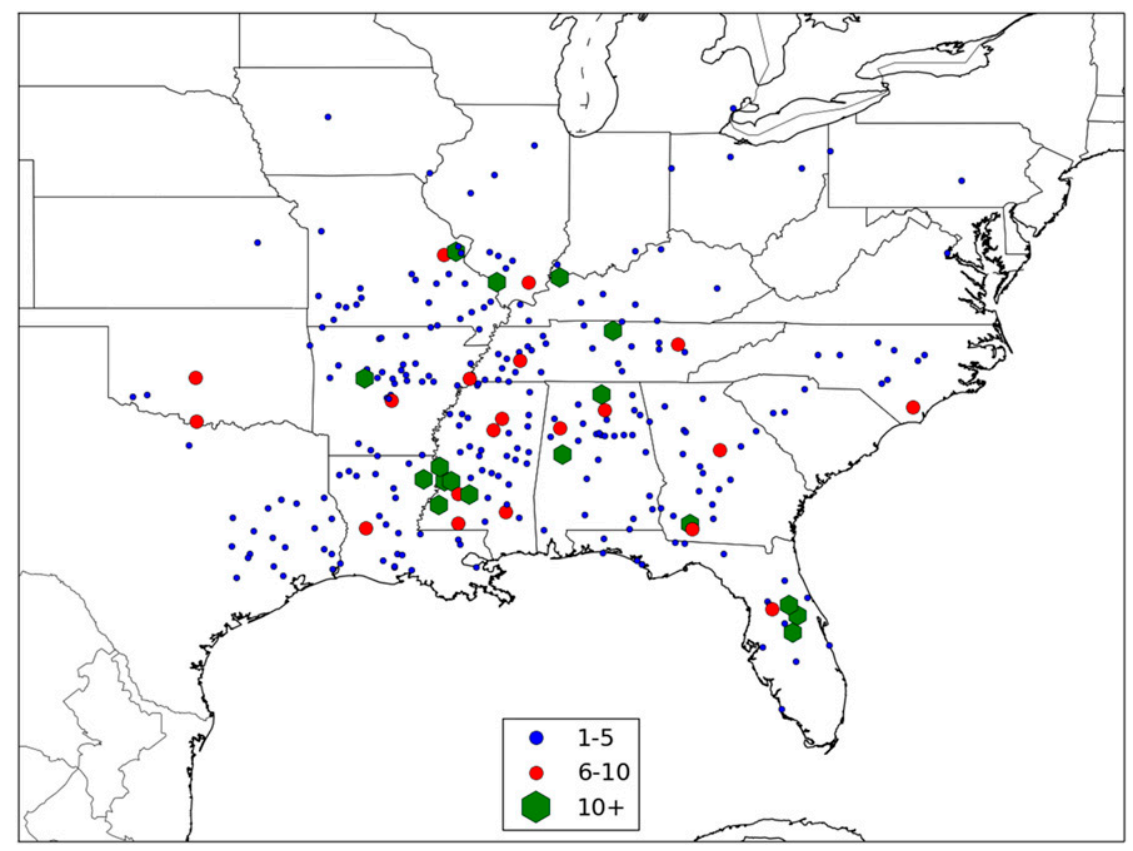

FIG. 1. Geographical distribution of NDJF tornado deaths (1953-2015) categorized by the number of deaths for a particular tornado.

(Paul et al. 2015) can lead to passivity and ignorance of tornado risk in the South and other regions. Adding insult to injury, Sherburn et al. (2016) show that severe weather watch and warning issuances are the least accurate during the winter. All of these factors culminate in cold-season tornadoes posing a greater risk for death and injury than spring and summer tornadoes across the United States, perhaps by more than 15\% (Simmons and Sutter 2008).

In recent work by Childs et al. (2018), the "cold season" is defined as the months of November-February (NDJF), the 4 months of the fewest average tornado counts across the United States (NCEI 2017b). This definition is retained here to establish the period over which a case study survey analysis is performed (i.e., November 2016-February 2017). Childs et al. (2018) showed that NDJF tornado frequency is increasing at a statistically significant pace over the past 62 cold seasons (1953-2015), with a geographic maximum increase stretching from central and western Tennessee southward along the Mississippi River. Over this same time period, within the domain of $25^{\circ}-42.5^{\circ} \mathrm{N}, 75^{\circ}-100^{\circ} \mathrm{W}$, some 937 people lost their lives as a result of NDJF tornadoes (Fig. 1). Some of these casualties occurred in major tornado outbreaks. Arguably the most prolific cold-season outbreak in modern history occurred on 21 and 22 February 1971 across the lower Mississippi Valley region. Nineteen tornadoes were confirmed, of which 13 were given an F2 rating or greater on the Fujita (F) scale [although work by Agee and Childs (2014) shows an overrating of weaker tornadoes prior to 1974]. This outbreak claimed 123 lives, with most fatalities attributed to the only F5 tornado to strike Louisiana in the modern record (Livingston 2012). The "Super Tuesday" tornado outbreak of 5 and 6 February 2008 had fewer deaths (57) but more total tornadoes (87) than the February 1971 outbreak (NOAA 2009). Even more recently, tornadoes that struck Mississippi and Texas around Christmas 2015 killed 26 people and injured more than 500, according to the Storm Prediction Center (SPC) Storm Data archives. Thus, although improvements in forecasting, safety, and awareness have occurred in recent decades, masscasualty cold-season tornado events are very real, dangerous, and growing concerns.

Given the propensity for NDJF tornadoes over the Southeast and Mississippi Valley regions, where some of the highest socioeconomic vulnerabilities exist in the United States, effective communication between weather professionals and the public in advance of and during a cold-season tornado event is imperative (Reynolds and Seeger 2005). Local emergency managers (EMs) also play important roles in community preparation, recovery, and resilience when a major tornado event occurs (Doswell et al. 1999; League et al. 2010). Numerous recent studies have discussed the importance of effective communication of natural hazards to the public (Morrow and Lazo 2016; Morss et al. 2015; Hogan Carr et al. 2016; Lazrus et al. 2016). People have been shown to respond 
based on their perception of the risk communicated; the specificity, frequency, and mode of communication; and their personal demographics and past experiences (Mileti and O'Brien 1992). Therefore, professionals must deliver a clear, consistent, complete, and relevant message for best compliance (Trumbo 2013). In fact, relationships with professionals can be of greater value to a person than his or her knowledge of the science or the accuracy of the forecast (Sherman-Morris 2005; Wall et al. 2017). Unfortunately, effective risk communication is easier said than done. Basher (2006) lists several barriers to effective communication of natural hazards, including dominance of the expert, public mistrust of warning systems or scientists, and lack of community feedback on communication strategies. Further, recent work by Demuth et al. (2017, manuscript submitted to Wea. Climate Soc.) revealed that in some cases of extreme weather, the professional decision-maker may hold a faulty view of how the public is receiving and responding to warning messages. Since the public ultimately must decide whether and how to respond to warnings (Sorensen 2000), decision-makers play a key role in presenting not only an accurate, but also a believable and action-initiating message that serves to protect lives and property during a major tornado event. It is in this context that a survey instrument was developed for professionals using real-time NDJF tornado events during winter 2016/17. This survey aims to increase understanding and reveal areas for improvement in tornado risk communication, specifically during the cold season, motivated by the following research questions:

(i) What barriers do professionals face when forecasting and communicating tornado risk during the cold season and in general?

(ii) What methods are employed by professionals to communicate the risk and warnings for a particular cold-season tornado?

(iii) How do professionals perceive public vulnerability, preparedness, and resiliency, both in the wake of a specific cold-season tornado and for tornadoes in general?

(iv) What can be done by the meteorological community to improve cold-season tornado risk communication and awareness?

The hope is that new understanding gleaned as a result of this study will help mitigate injuries and fatalities from tornadoes during all times of the year. The rest of this article is organized as follows: section 2 describes the methods regarding development and deployment of the survey instrument. A summary of the four case studies from November 2016 to February 2017 is given in section 3. Results from content analysis of the survey responses are reported in section 4 through creation of a conceptual model of tornado risk communication. Finally, a summary, limitations and opportunities for future work, and implementation are discussed in section 5 .

\section{Methodology}

Studies that assess tornado risk communication, specifically those that employ quantitative methods such as surveys, have been gaining popularity in recent years (NOAA 2016). However, this study goes beyond quantitative results by offering experts a chance to answer open-ended questions regarding the methods and barriers in communicating risk for a specific cold-season tornado event that occurred in their area. Such an approach is similar to the normative-descriptive-prescriptive framework put forward by Fischhoff and Kadvany (2011) and applied to public perception of visual tornado clues by Dewitt et al. (2015). That is, given the known challenges and barriers to communicating severe weather risk (normative), professionals are asked to describe their perceived barriers to communicating cold-season tornado risk (descriptive), which can then be analyzed to search for ways to improve communication methods (prescriptive). A difference here is that the perception of the professional, not the public, is targeted. Obtaining the public perception would more completely fulfill the descriptive component of this framework. The survey instrument is designed for three professional sectors in particular, to be deployed immediately after major cold-season tornado events. The three sectors include National Weather Service (NWS) meteorologists from local Weather Forecasting Offices (WFOs), television/broadcast meteorologists, and emergency management officials. Morss et al. (2015) interviewed professionals from these same three groups in their study of flash-flooding risk perception and communication. The end goals of the work presented here are to uncover perceived barriers in tornado risk communication, in particular but not limited to the unique subset of NDJF tornadoes, and to assess public vulnerability and preparedness as perceived by professionals. The results are then visualized into a conceptual model of tornado risk communication.

\section{a. Selection of domain and participants}

The spatial domain chosen for this study is $30^{\circ}-37.5^{\circ} \mathrm{N}$, $85^{\circ}-95^{\circ} \mathrm{W}$, as shown in Fig. 2. This domain captures the area where the vast majority of cold-season tornadoes occur and are increasing in frequency (Childs et al. 2018). Following a purposive sampling approach, professionals were contacted in fall 2016 via an email that explained the research project and sought their willingness to 


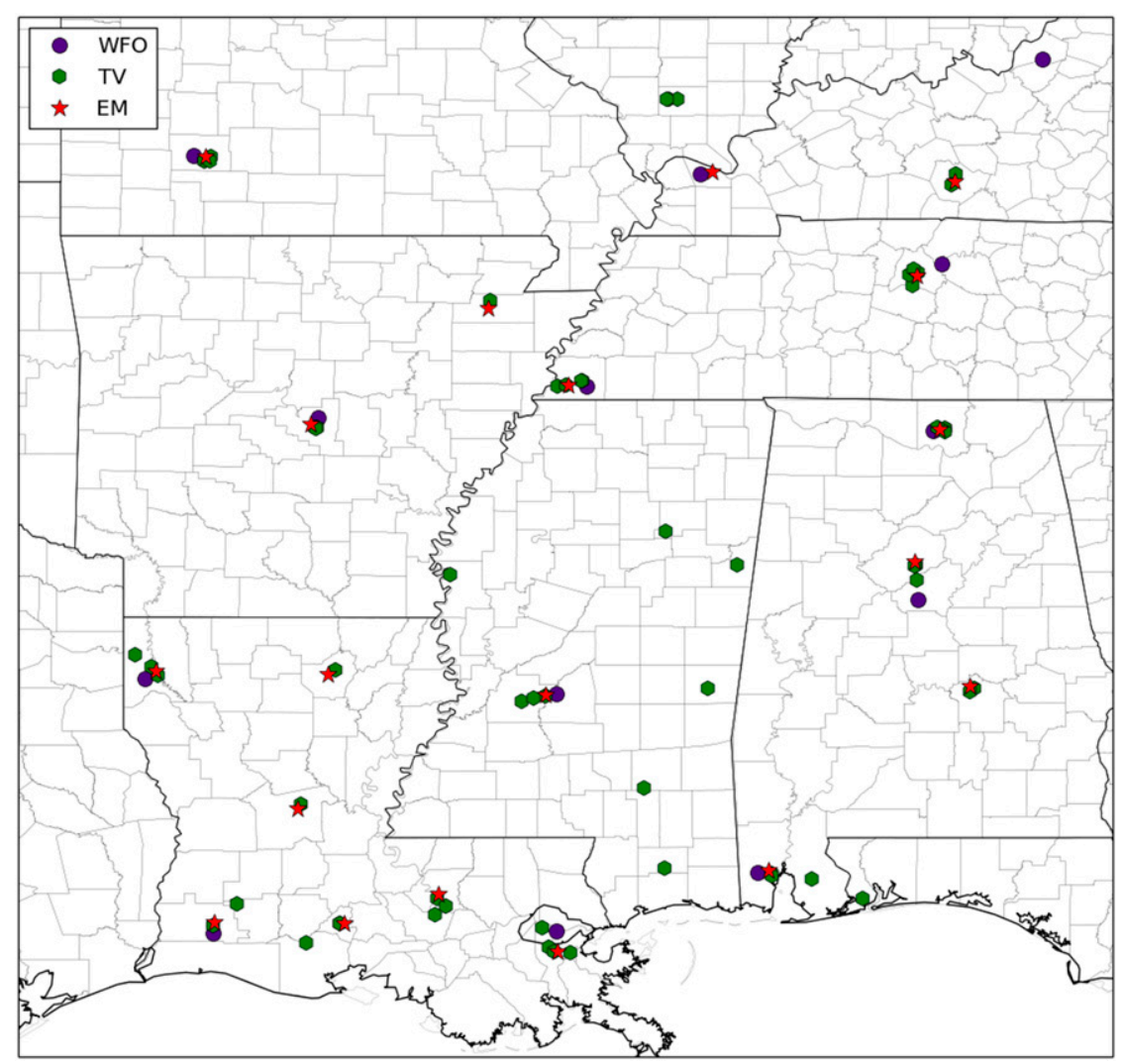

FIG. 2. Locations of NWS WFO offices (circles), television stations (hexagons), and EM offices (stars) from which survey participants were initially sought.

participate. In all, 12 WFOs, 63 major television stations (i.e., network affiliates of ABC, CBS, FOX, and NBC), and 24 emergency management offices within the study domain were contacted to solicit meteorologists and EM personnel (Fig. 2). By 1 November 2016, the official start of the 4-month study period, 33 professionals (at least four from each sector) from across the domain had indicated their willingness to participate if called upon.

\section{b. Survey composition and deployment}

Three similar yet distinct surveys were written and administered via the online survey software QuestionPro (www.questionpro.com). Each survey was given a unique web address to add professionalism and ease of access. To protect privacy, each survey was identified with a number rather than a respondent's name. This also prevented a person from taking or finishing a survey begun by another person. All survey data and reports were stored within the QuestionPro interface and were accessed and analyzed only by the researchers in this study. The Colorado State University Institutional Review Board approved this study in June 2016, noting that the risks involved were minimal.
The surveys consisted of 23 (NWS, TV) or 25 (EM) questions, a few with multiple parts, and were designed to take approximately $1 \mathrm{~h}$ to complete. For reference, the NWS meteorologist survey is included in the online supplement (available at the Journals Online website: https://doi.org/10.1175/WCAS-D-17-0073.s1). Some questions were open-ended, and others asked the professional to select a multiple-choice option or provide a 0-10 scale rating. The first few open-ended questions addressed communication strategies and challenges faced by the professional during the event in question, as well as his or her collaboration efforts with other decisionmaking sectors. Next, a series of closed-ended questions asked the professional to rate how he or she felt their community was warned, prepared for, and responded to the tornado event. The professional was then asked what he or she learned in regard to cold-season tornado risk communication from the event in question. Approximately the second half of the survey aimed to paint a broader picture by asking how the professional perceived the local vulnerability and public receptivity to tornadoes in general. In addition, the professional's perception of his or her own personal awareness of the 
increasing risk from cold-season tornadoes in the South and Southeast, as well as his or her perception of public awareness, was assessed. A final question asked the professional what could be done to improve outreach and communication of cold-season tornadoes from his or her specific office/station and the meteorological sector as a whole. The survey ended by asking for the professional's contact information if he or she would be willing to participate in a follow-up interview, if necessary. In the end, no follow-up interviews were conducted since a sufficient sample was achieved.

Tornado risk within the study domain was monitored throughout November 2016-February 2017, the defined cold season for this study. When a tornado event occurred, its significance was determined based on researcher discretion. In general, a tornado event was deemed worthy to warrant survey deployment if multiple tornadoes occurred within a small area, if at least one significant tornado [EF2+ on the enhanced Fujita (EF) scale] occurred, or if there was major damage or casualties (or a combination of these). When such a scenario transpired, an email containing the QuestionPro survey link was sent to those professionals within the affected area who had indicated willingness 3-5 days after the tornado event, to allow time for initial community response and recovery efforts. In addition, the survey link was resent to chief meteorologists or MICs in the affected area who did not initially respond and sent for the first time to EM offices of the specific counties impacted. The professionals contacted were also asked to disseminate the survey link throughout their offices or stations in order to reach all who had a role in forecasting or responding to the event in question. It should be noted that surveys given after an event may be suspect due to memory loss of the respondent, outcome bias (Fischhoff and Davis 2014), and bias toward local area demographics and culture that could distort a more general opinion (Simmons and Sutter 2008). Nevertheless, postevent surveys that gauge the professional and/or public perception are common in hazards risk literature (e.g., Zhang et al. 2007; Morss and Hayden 2010; Morss et al. 2015, 2016; Demuth et al. 2017, manuscript submitted to Wea. Climate Soc.). Since only certain parts of the domain were impacted by a major tornado event over the study duration, some of the willing participants were never recontacted. Effort was also taken to refrain from sending a survey to the same professional more than once during the study period, even if an area experienced more than one event. This requirement resulted in a major tornado event in Hattiesburg, Mississippi, being bypassed because of an earlier event occurring in the same area. The professionals were asked to complete and submit the online survey within 1 month, while recollection of the tornado event remained easy. Over the four cases analyzed in winter 2016/17, survey links were sent to five WFOs, 17 television stations, and 14 EM offices, with the anticipation that at least two professionals from each office or station would have been directly involved with communicating the tornado risk and therefore could have feasibly taken the survey.

\section{c. Quantitative and qualitative methods}

Simple quantitative statistical analysis was performed on the closed-ended questions, such as comparing the means of $0-10$ scale responses. Qualitative analysis of open-ended survey questions followed a similar approach to that of Morss et al. (2015). First, responses were separated into categories based on the key research questions, such as barriers to communication, receptivity and response of the public, relation to physical meteorology, vulnerability, and action steps. Next, a content analysis was performed by carefully combing the responses for similar words and phrases in order to extract common themes and factors that fell under one or more of the larger categories. Finally, these common themes were summarized, and the categories subsequently condensed, to arrive at a conceptual model of tornado risk communication from the professional perspective, to be discussed in detail in section 4 .

\section{Summary of events}

The winter of 2016/17 proved to be a very active tornado season in the United States, providing several opportunities for case studies. A total of 270 EF0-EF5 tornadoes occurred during NDJF 2016/17 (SPC 2017), which places the season squarely within the top 10 most tornadic of all cold seasons in the now-63-yr data record. Further, the January 2017 monthly total of 134 tornadoes makes it the second most tornadic January on record (NCEI 2017a). While there are likely many factors that influenced the enhanced activity, it should be noted that the winter of 2016/17 was characterized by a weak La Niña and a positive-phase Arctic Oscillation (AO), two conditions that have been shown to promote elevated wintertime tornado counts (Cook and Schaefer 2008; Allen et al. 2015; Childs et al. 2018).

In all, four events were sampled throughout the study period, and Fig. 3 shows the associated tornado tracks and EF-scale ratings. November 2016 began with the continuation of a persistent ridge over most of the western and central United States, with the storm track confining the only meaningful precipitation to the Northeast and Northwest. Abnormally high temperatures prevailed over much of the country, and much of the Southeast was under severe drought. By the end of November, the pattern began to shift toward more 


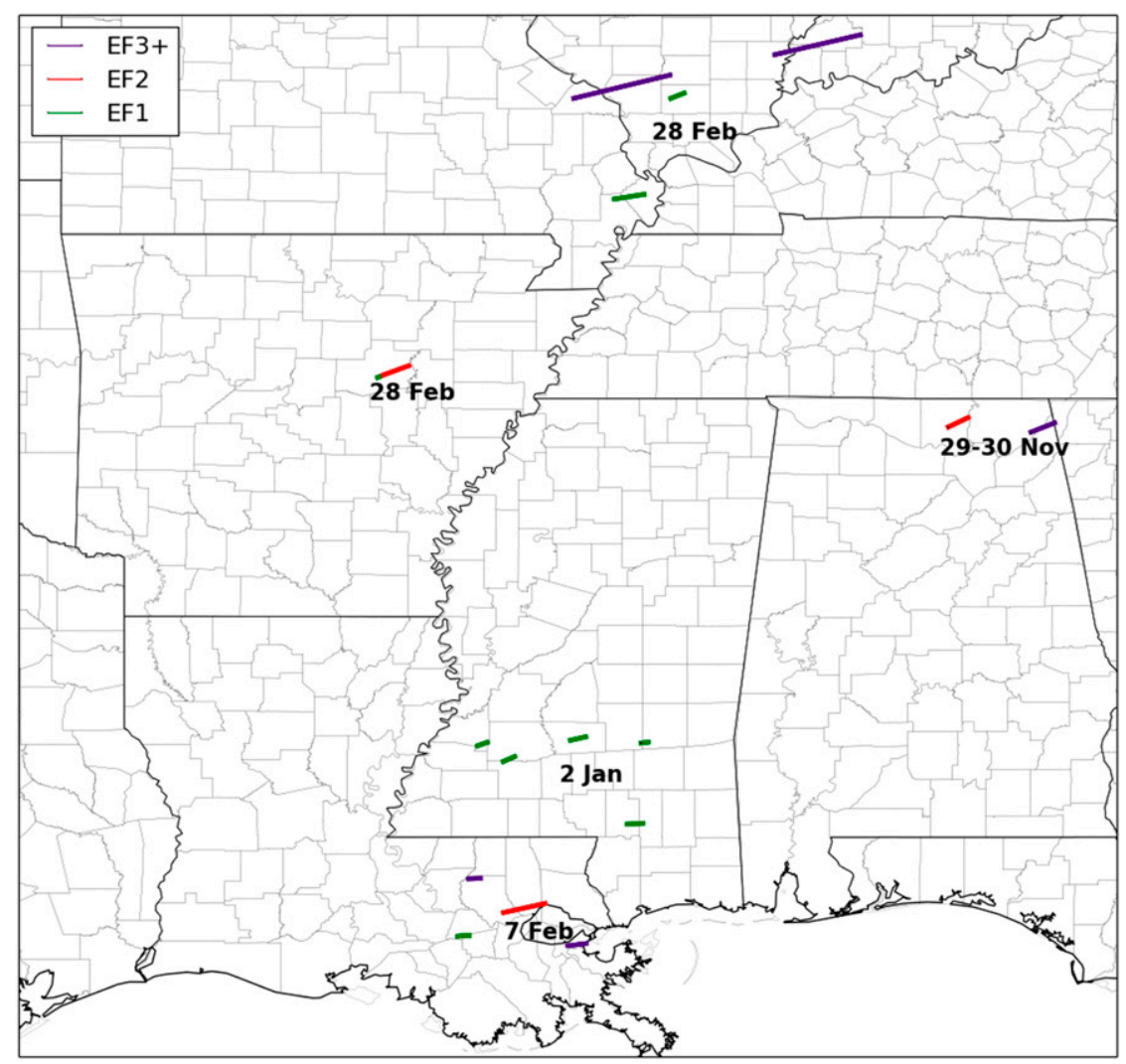

FIG. 3. Tornado tracks for the four NDJF case studies, color coded by EF-scale intensity.

extratropical cyclone progression across the country, leading to a stormier regime. Outside of the study domain, tornadoes were reported in Nebraska and Iowa in late November, quite a rare occurrence for these areas. On the evening of 29 November, the SPC convective outlook highlighted a moderate risk for severe weather with a $15 \%$ significant tornado contour across northern Mississippi, with a $10 \%$ significant tornado contour stretching into northern Alabama. This amplified risk verified, as a long-track EF3 tornado devastated the small communities of Rosalie and Ider, Alabama, east of Huntsville, in the early morning hours (around 0600 UTC) of 30 November, resulting in three fatalities. Another significant tornado tore a path through the eastern fringe of Madison County, where Huntsville is located. In all, 45 tornadoes were confirmed on 29 and 30 November across Mississippi, northern Alabama, and southern Tennessee, with many of those obtaining EF2 ratings. As such, the 29 and 30 November killer EF3 Rosalie-Ider and Madison County tornadoes became the first event for survey deployment. This case also affirmed the high vulnerability of the Southeast due to nocturnal tornadoes over rural, forested areas (Paul et al. 2003; Ashley et al. 2008).
Following the late November outbreak was a quieter period, with several surges of Arctic air penetrating southward into the United States. While December proved to be a very inactive tornado month, January 2017 was quite the opposite. On 2 January, 35 tornadoes were reported across the Deep South, including eight damaging tornadoes (one EF2) that swept across a fairly localized area of southern Mississippi around midday, which became the focus of the second case study. Thankfully, no casualties or injuries were reported in these tornadoes, but a tornado in southeastern Alabama on the same day did kill four people. (This tornado was not analyzed due to its occurrence on the edge of the domain.) A very active week then occurred from 15 to 22 January, with over 50 tornado reports. Of note, a large EF3 tornado killed four people and injured 56 in Hattiesburg, Mississippi, on 20 January. As mentioned, this tornado was not included in the study because the same area had already been sampled during the 2 January tornadoes. Killer tornadoes also struck southern Georgia, outside the study domain, on 21 and 22 January. In the end, January 2017 recorded 134 official tornado reports, the second highest January count since 1950 (NCEI 2017a). 
February 2017 provided the final two case studies. On 7 February, 17 tornadoes were reported, scattered throughout the Mississippi Valley region. The greatest impacts were felt in southeastern Louisiana, where two EF3 tornadoes, one in east New Orleans and one in Livingston Parish, caused major damage and at least 30 injuries, yet miraculously no fatalities. The EF3 tornado in east New Orleans was the strongest tornado ever recorded in Orleans Parish since records began in 1950. The middle part of February was fairly inactive across the domain, although a few rounds of tornadoes occurred in Texas. The very last day of the study period provided the final case from a tornado outbreak that spanned 28 February1 March, impacting a swath from central Arkansas northeastward into Missouri, Illinois, Indiana, Kentucky, and Michigan. Over 80 tornadoes were reported over these 2 days, with several significant tornadoes and three that resulted in fatalities. This final survey deployment specifically targeted two tornadoes in White County, Arkansas (just northeast of Little Rock), that injured four people and a series of tornadoes stretching from southeast Missouri into southern Illinois and southern Indiana. This includes the only EF4 tornado of the 2016/17 winter season, a multivortex twister that touched down in Perry County, Missouri, and traveled some 50 miles northeastward across the Mississippi River into Illinois, making it the longest track tornado in the Paducah, Kentucky, WFO domain since 1981. Additional significant and killer tornadoes across north-central Illinois in this outbreak were outside of the study domain. To summarize, the four cases for which surveys were deployed were as follows: 1) RosalieIder, Alabama, hereafter 29NOV-AL; 2) southern Mississippi, hereafter 2JAN-MS; 3) southeast Louisiana/east New Orleans, hereafter 7FEB-LA; and 4) upper Mississippi Valley (Arkansas/Missouri/Illinois/Indiana), hereafter 28FEB-UPMSV (Fig. 3).

\section{Results}

\section{a. Participant statistics}

Despite only sending surveys to the nearest WFO, three to six local television stations, and three to five EM offices for each event, professionals in general seemed eager to provide feedback. Seventeen surveys were able to be analyzed, many of which contained lengthy and thoughtful responses to the open-ended questions. While sample sizes were too low to claim that a representative sample was reached in any one case, when the four cases are taken as a whole, many repeated ideas and comments surfaced for many of the questions. This gave confidence that saturation had been achieved with the 17 respondents and analysis could be adequately performed, as additional professionals would not have
TABLE 1. Distribution of NWS, broadcast, and EM surveys viewed, started, and completed for case 1 (29NOV-AL), case 2 (2JAN-MS) case 3 (7FEB-LA) and case 4 (28FEB-UPMSV). The total number of completed surveys for each case is given, as well as the total number of incomplete (i.e., started but not finished) surveys in parentheses.

\begin{tabular}{llcccc}
\hline \hline \multirow{2}{*}{ NWS } & Case 1 & Case 2 & Case 3 & Case 4 \\
& Viewed & 8 & 4 & 0 & 2 \\
& Started & 5 & 1 & 0 & 2 \\
TV & Completed & 4 & 1 & 0 & 2 \\
& Viewed & 6 & 29 & 34 & 5 \\
& Started & 3 & 2 & 4 & 3 \\
\multirow{4}{*}{ EM } & Completed & 2 & 2 & 2 & 3 \\
& Viewed & 5 & 1 & 0 & 0 \\
& Started & 1 & 0 & 0 & 0 \\
\multirow{2}{*}{ Total completed } & Completed & 1 & 0 & 0 & 0 \\
\hline
\end{tabular}

provided any new information critical to the creation of the conceptual model (Bertaux 1981). Across the board, emergency management officials were least responsive, with only one complete response over the four cases. The relative scarcity of EM personnel in the locations sampled, combined with the busyness of postevent surveys and resiliency efforts, may have precluded more participation from this group. Broadcast and NWS meteorologists responded in greater numbers for each case study. Table 1 summarizes the participant statistics from the four cases, highlighting the number from each professional sector that viewed, started (and dropped out), and finished the survey in its entirety. The total number of survey responses either completed entirely or partially (in parentheses) for each case is also given. Qualitative and quantitative analysis is performed on open-ended responses up to the point of dropout for partially completed surveys. Though it is not possible to know why, it is intriguing that many broadcast meteorologists viewed the survey (i.e., opened the link) but did not choose to start. Time commitments ranged from an average of $14 \mathrm{~min}$ to $1 \mathrm{~h}$.

\section{b. Conceptual model of common themes}

The qualitative analysis performed on each set of responses began with coding open-ended questions by hand; that is, frequently used words and concepts were documented. These common ideas were then placed into categories according to the key research questions, an often-used strategy in content analysis (Weber 1990). Upon further analysis of the responses, it was seen that professionals highlighted a number of factors that served as communication barriers. These factors were also related to how the professional perceived the local vulnerability to tornadoes. Action steps provided by 


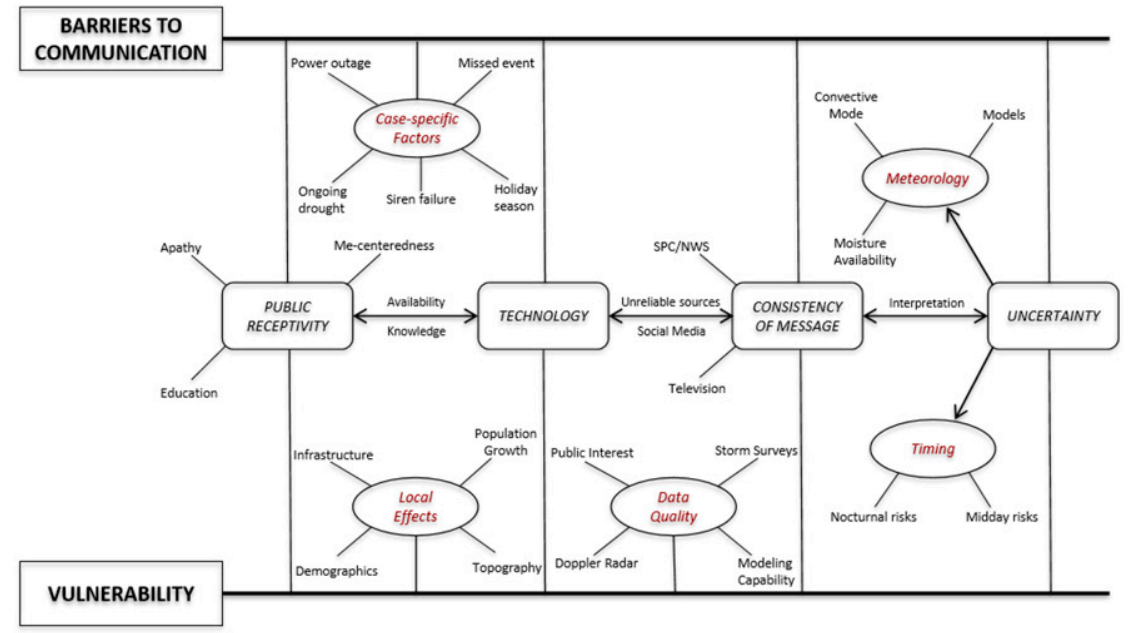

FIG. 4. Conceptual model of tornado risk communication. The two large rectangles on the left represent two main categories of analysis ("barriers to communication" and "vulnerability"); the four rounded rectangles represent factors that influence both categories (and that are also interrelated via the double arrows); straight-line appendages point to specific components within a factor; the ovals represent factors that play a role in only one of the categories, with their specific components marked by straight-line appendages; and the ovals connected to the "uncertainty" factor represent two main sources of uncertainty that influence both categories, with straight-line appendages pointing to specific components of these uncertainties.

the professional were also grouped according to common ideas and summarized. Overall, the professionals did not perceive major differences in their barriers to and approach toward communicating risk for coldseason cases compared to tornadoes in general. For example, for the four case studies combined, $59 \%$ of professionals said that their difficulty in forecasting cold-season tornadoes was similar to that of all tornadoes, and $88 \%$ of professionals believe the public shows similar receptivity to cold-season tornadoes as they do to tornadoes in general. Thus, while coldseason tornadoes certainly present unique challenges to professionals (which will be addressed below), the survey responses better serve as an opportunity to pinpoint and visualize tornado risk communication barriers, from the professional perspective, using actual real-time case studies. As such, a conceptual model of tornado risk communication was created (Fig. 4) with four factors (public receptivity, technology, consistency of message, and uncertainty) influencing two main categories of "barriers to communication" and "vulnerability." Barriers unique to one particular case are captured within the conceptual model as "casespecific factors." In addition, the professional's perception of vulnerability is influenced by several local characteristics and data quality, as shown in Fig. 4. Although limited by the study's focus on the cold season, its localized Southeast U.S. domain, and its formulation based on only 17 professional responses, this conceptual model can be of great value to professionals in tornado risk communication roles by providing a visual representation of the obstacles that must be overcome, along with the potential impacts those obstacles have on public vulnerability. The main features of the conceptual model will now be discussed in detail, using actual quotations from professionals.

\section{1) BARRIERS TO COMMUNICATION}

Case-specific barriers to effective tornado risk and warning communication were plentiful in the four cases (Fig. 4, upper left). The 29NOV-AL event in particular presented unique obstacles for meteorologists. Several professionals mentioned the highly publicized ongoing drought (Hersher 2016) - which also led to a devastating wildfire in nearby Gatlinburg, Tennessee-and cool temperatures leading up to the event, making the forecast of rain and warmth encouraging to residents. In the words of one NWS meteorologist, "this was our first sizable rain event [in] months, so folks may have fixated on that first" (NWS1.1 ${ }^{1}$ ). In addition, the SPC enhanced risk of severe weather with $5 \%$ tornado contour did not

\footnotetext{
${ }^{1}$ Hereafter, this nomenclature will be used to reference individual respondents. The citation will begin with TV, NWS, or EM to refer to the specific group of professionals, followed by a number between 1 and 4 to refer to the specific tornado case, followed by another number indicating the individual. For example, NWS1.1 refers to the first NWS meteorologist respondent from case 1.
} 
verify well the previous day (28 November) across Mississippi. The 29 November morning convective outlooks had only a slight risk across Mississippi and northern Alabama before SPC ramped up the threat to include a moderate risk for severe weather with a $15 \%$ significant tornado contour across northern Mississippi by evening, with an enhanced risk and $10 \%$ significant tornado contour stretching into northern Alabama. This forced forecasters to make quick adjustments in communicating the tornado risk. This case was also challenging for the professionals because of electrical issues. A sizeable power outage limited television and internet communication and put the Huntsville NOAA weather radio transmitter, which provides the best coverage for the affected counties, offline. Local warning sirens also failed to sound. Finally, the deadly tornadoes occurred around midnight local time, after most people had gone to bed. Without electricity, people had to rely upon their phones to wake them up with weather alerts, making those who did not own smartphones or have other access to weather warnings more vulnerable. As a result, one broadcast meteorologist stressed the importance of having "multiple ways to receive weather alerts" and checking on family or friends who may not be aware (TV1.3). As hypothesized earlier, the hustle and bustle of the holidays can also cause people to let their guard down. Sure enough, for the 2JAN-MS case, one broadcast meteorologist remarked, "coming out of a holiday weekend, it was most difficult just to get people's attention" (TV2.1).

Other reported barriers to communication were common throughout the four cases and are packaged under the four factors in Fig. 4 (middle row). One such factor is public receptivity, or how the public actually receives the tornado risk and warning information. While a sampling of the public is needed to affirm the accuracy of the professional perceptions, most professionals expressed the view that their local public is well educated and aware of cold-season tornado risk and, therefore, was not surprised by the tornado event in question. In the 29NOV-AL case, NWS meteorologists mentioned that most people are "very aware of and prepared for tornadoes" (NWS1.3) and that the public is "keen on severe weather" (NWS1.2). This opinion was also shared by broadcast meteorologists in the Huntsville, Alabama, market. According to one meteorologist, "Most people who have lived in Alabama know that there is normally a 'second' severe weather season in the fall, [and] I was pleasantly surprised by the amount of people who took the warnings seriously" (TV1.3). Meteorologists in other cases also tended to perceive the local public as aware of the risk and apt to heed warnings. TV2.1 from the 2JAN-MS case commented that "people down here take tornadoes seriously"; TV4.3 from the 28FEB-UPMS case relayed that "viewers are used to nighttime/"cold-season' outbreaks and know they can be serious"; and according to NWS2.1, "folks are not surprised when [cold-season tornadoes] happen." Interestingly, the one EM who completed a survey had a very different view on public receptivity. This EM expressed that "the biggest challenge we face is a lack of education with the public" and that "they just ignore our warning." He further noted that "almost no citizen [has] any awareness of recovery resources, how to locate them, or how to use them." He even reported that only $10 \%$ of his county population has opted into the mass warning communication system and that several people called to remove their information after the event "because [the system] woke them up." Though a greater EM response would have validated (or not) this EM's frustration, it is reasonable to conceive that EMs could hold a different view of public receptivity than meteorologists. One possible reason for different perspectives is an "urban versus rural" paradigm. Almost all of the meteorologists sampled work in urban areas, yet most of the counties impacted by tornadoes during the study period were rural (and, in fact, the EM respondent was from a rural county). Thus, there may be a skewed perception of public awareness and receptivity by meteorologists in urban areas, whereas EMs in more direct contact with small, rural populations may sense that the public is not as educated or receptive. If true, this conflicting perception among professionals is a potential hindrance to public safety, and further work that involves sampling the public in both urban and rural areas to see how people actually receive and respond to tornado warnings is warranted.

Despite the general perception of high public receptivity, several professionals mentioned a barrier that TV1.2 aptly called a "me-centered universe." Perhaps NWS1.4 said it best: "I honestly feel like some people think we can look into a crystal ball and tell them precisely when a tornado will be in their neighborhood." Surely, someone would want to know exactly if and when a tornado was going to strike his or her home, but in reality, no meteorologist is able to deliver this level of precision. As a broadcast meteorologist in the 29NOV-AL case put it, "The main barrier is getting people information in the way they want it, which is basically impossible from a scientific perspective" (TV1.2). This "me-centeredness" acts as a barrier because the professional must craft his or her warning message in such a way as to make it as personal as possible, while at the same time communicating the scientific nature of the risk. Otherwise, the public may become frustrated and disengage, which could be interpreted by professionals 
as apathy or complacency. Affirming this professional perception are studies that show that personalization of the warning message (Brotzge and Donner 2013) and geographic specificity (Nagele and Trainor 2012) are important factors not only in public response to tornado warnings, but also in other short-term weather hazards, such as flash floods (Morss et al. 2015).

The availability and understanding of technology in today's ever-modernizing society also affects public receptivity and is itself a barrier to communication. This is realized in the exorbitant number of pathways for communicating tornado risk, as affirmed by several professionals. For example, the EM mentioned three mass communication options available to the public through his county and state EM agencies, along with three major television markets in the county's listening area, each of which is served by a different WFO. Similarly, TV1.1 mentioned that "TORCON from the Weather Channel, the multi-tiered threat level information from local NWS offices ... on top of the tiered SPC risks ... muddy the water." With the plethora of options for receiving tornado warnings comes an elevated risk for misinterpretation or believing unreliable sources. One is easily enticed to simply choose his or her favorite source based on factors like aesthetically appealing graphics or the on-air weather personality, even if the message delivered conflicts with another source. The idea that the public develops relationships with television personalities is not new. Horton and Wohl (1956) originally coined the phenomenon "parasocial interaction," and it has been shown to play a large role in public receptivity (Schramm 2008; Schramm and Hartmann 2008). Applied to meteorologists, a public survey conducted in the Memphis, Tennessee, market found that over time, people form a relationship with their local television meteorologist and, in turn, trust him or her in times of severe weather (Sherman-Morris 2005). Hence, there exists a need to "work toward a single message, otherwise the public gets inundated with so much information they ignore it all" (EM). Obtaining the public perspective would be helpful in confirming whether this is indeed the case, but it is revealing that professionals across multiple cases cited "consistency of message" as a key barrier. The increasing social media influence is also affecting meteorologists in real-time warning dissemination. When describing a challenge faced during the 7FEB-LA case, TV3.1 mentioned that "the added demands of on-air plus social media connectivity are stretching capabilities of meeting the expectations of timely posting of notices on all information platforms." This is a concerning admission that warrants further investigation, especially as social media becomes more popular and widely used by the public.

A final barrier repeatedly cited by professionals is that of uncertainty, which Morss et al. (2015) also showed to be a major factor in risk communication. Here, uncertainty manifested itself primarily in two realms (Fig. 4, middle right). First, there were uncertainties regarding timing of the cold-season events. The 29NOV-AL event was nocturnal, adding the difficulty of alerting people as they slept. As TV1.3 put it, "The hardest thing was that we knew it was going to be an overnight event, and stressing to people to either stay up late or be aware." In the 7FEB-LA case, TV 3.1 reported that the unique "mid/late morning timing of the outbreak . . made connectivity to the public more difficult." A second uncertainty manifested itself in the meteorology. Professionals across all cases mentioned that communicating the tornado risk would have been easier if there were a better understanding of, for example, "how far north the warm moist air [would] make it" (TV2.1) and "the typical questions concerning boundary layer moisture return and instability that we have in the winter" (NWS2.1). NWS1.4 addressed the difficulty of forecasting storm mode: "Forecasting the mode of convection ... was also a significant challenge. I think that we were a little unclear about whether we would be dealing with a linear band of convection or individual cells. When it became clear that we would see more supercellular-type convection in the open warm sector, the threat for significant tornadoes became more apparent." These forecasting challenges are consistent with the meteorological factors found to be associated with cold-season tornadoes. For example, it is shown that NDJF tornadoes arising from discrete cells result in higher human casualty than those from linear systems, yet they occur around the same frequency (Childs et al. 2018), so having a better idea of the expected storm mode would allow for more precise communication of the tornado risks. The utility of models in providing improved understanding of convective mode (and severity) was addressed by a few professionals. While TV3.2 described the 7FEB-LA case as "an event that models did not even notice," TV4.2 reported that "model agreement/consistency leading up the [28FEBUPMSV] event made the event fairly easy to prepare for and led the public to being well prepared to take action." It should be noted that the four main factors reported by professionals as creating barriers to tornado risk communication are not limited to the cold season, but extend to any time of the year, giving the conceptual model in Fig. 4 a broader utility.

\section{2) VulNERABILITY}

Uncovering the professional perception of local vulnerability is another research goal of the survey content analysis and is displayed as the second main category in Fig. 4. As expected, given the Southeast domain, professionals mentioned several local effects as contributing 
to public vulnerability (Fig. 4, lower left). For the 29NOV-AL case, professionals cited the "poverty/ education/rural communication" (NWS1.1) of northern Alabama and "substandard construction" (NWS1.3). Further, in the 28FEB-UPMSV case, TV4.3 mentioned that the "largely rural area with lots of manufactured housing [make the area] more vulnerable to damage," referring to the tristate (Illinois/Kentucky/Missouri) region. These responses align with recent studies linking nonmeteorological factors to increased vulnerability in the Southeast (Ashley 2007; Emrich and Cutter 2011; Ashley and Strader 2016).

Other factors influencing perceived vulnerability include those already mentioned above associated with barriers to communication. For example, lower education levels can lead to reduced receptivity and thus make a community more susceptible to tornadoes. While measuring public response, given that one has knowledge of local tornado risks, is complex, at least one study has shown that an awareness of tornado risk decreases demand for manufactured homes (Sutter and Poitras 2010). A changing population density also impacts the level of tornado awareness. For instance, TV2.1 expressed a concern that "a lot of people are moving here [i.e., southern Mississippi] without the knowledge that tornadoes happen year-round." This perception is consistent with work that shows that as population density changes and cities and towns expand, more people are becoming exposed to tornado and natural hazards risks (Anderson et al. 2007; Donner and Rodríguez 2008; Ashley et al. 2014; Ashley and Strader 2016; Strader et al. 2017). Limited access to technology also makes one more vulnerable, as do misinterpretation of messages and belief in appealing yet unreliable sources. These factors confirm the need for improved education to help the public understand tornado risk and know how to discern reliable sources. Vulnerability increases with uncertainty in timing as well, particularly in the Southeast cold season, with its propensity for nighttime tornadoes. As discussed earlier, overnight tornado events during the winter highlight the need for people to have available and reliable technology to alert them during these hours. If they do not, their susceptibility to tornado impacts rises (Ashley et al. 2008).

As with barriers to communicating tornado risk, the factors influencing perceptions of vulnerability can be applied to all tornadoes. However, given the cold-season perspective of this study, professionals were asked to give their perception of local vulnerability to cold-season tornadoes in particular. Although most professionals reported a high local public vulnerability to cold-season tornadoes overall, fewer than half of professionals (41\%) expressed the view that vulnerability is increasing over time. As for why this belief of a "stable" vulnerability exists, many professionals cited advancements in data quality, utility of Doppler radar, modeling capability, more public storm shelters, and increasing public interest and awareness as counteracting the increase in NDJF tornado reports (Fig. 4, lower middle). Interestingly, when asked whether they were aware of the increasing frequency of cold-season tornadoes in the Southeast and Mississippi Valley regions (Childs et al. 2018), only $44 \%$ of professionals acknowledged personal awareness and 35\% perceived the public to be aware. It seems that many professionals believe this increasing trend in NDJF tornadoes is a result of "more frequent and aggressive poststorm survey efforts" (TV3.1), "better reporting" (TV1.1), and "higher identification of cold-season and weaker tornadoes" (TV2.2). Still, the survey responses reveal that professionals perceive a high public vulnerability overall to tornadoes in the Southeast and Mississippi Valley regions, which is further enhanced during the cold season, as discussed below.

\section{Discussion}

\section{a. Summary of survey analysis}

Quantitative results from survey questions that asked professionals to rate the public awareness, preparedness, vulnerability, and receptivity regarding coldseason tornadoes and/or tornadoes in general provide a good summary of the overall perceptions. Table 2 lists the average ratings and ranges of these and other measurements on a scale from 0 to 10 of all professional sectors for each case, as well as the averages of all cases combined. It is seen that although professionals view their communities as vulnerable to tornadoes in general (7.7/10), they also perceive the public to be well prepared (7.1/10) and receptive to risk messages (8.6/10). Further, the public is viewed as very resilient to specific cold-season tornado impacts (8.4/10). Individual perceptions were largely consistent between NWS and broadcast meteorologists, although the EM respondent for the 29NOV-AL case rated community preparedness (3/10) and receptivity (4/10) much lower, likely due to his view that the public in his county lacks education and does not take advantage of mass communication resources. The low ratings of adequate public warning (3.3/10) and preparedness (3.0/10) expressed by meteorologists in the 7FEB-LA case were likely because of the surprise nature of that event.

Several barriers to effective cold-season tornado communication surfaced in the survey responses. Some were case-specific, such as power and siren failures, an ongoing drought, the holiday season, and overnight 
TABLE 2. Average perceptions of professionals of their communities for various measures and factors related to the specific NDJF tornado event and tornadoes in general. Results are reported as the mean (on a 0-10 scale) from all professionals, with the range of ratings in parentheses, for each case.

\begin{tabular}{|c|c|c|c|}
\hline & Warned & Prepared & Resilient \\
\hline Case 1 & $6.4(3-8)$ & $5.6(2-9)$ & $8.5(6-10)$ \\
\hline Case 2 & $8.3(7-9)$ & $7.3(7-8)$ & $9.0(8-10)$ \\
\hline Case 3 & $3.3(2-5)$ & $3.0(1-5)$ & $5.5(3-8)$ \\
\hline Case 4 & $9.2(8-10)$ & $8.4(6-10)$ & $9.2(8-10)$ \\
\hline Total & 7.2 & 6.4 & 8.4 \\
\hline \multicolumn{4}{|c|}{ (b) On a scale from 0 to 10 , how ___ do you feel your communities are to tornadoes in general? } \\
\hline & Vulnerable & Prepared & Receptive \\
\hline Case 1 & $8.3(7-10)$ & $7.7(3-10)$ & $7.6(4-10)$ \\
\hline Case 2 & $8.7(7-10)$ & $8.0(7-9)$ & $10.0(10)$ \\
\hline Case 3 & $5.0(5)$ & $3.0(3)$ & $10.0(10)$ \\
\hline Case 4 & $7.4(7-8)$ & $7.4(6-9)$ & $8.6(7-10)$ \\
\hline Total & 7.7 & 7.1 & 8.6 \\
\hline
\end{tabular}

timing. Repeatedly perceived barriers included the "mecenteredness" of people who desire to know exactly when and where a tornado will strike and whether they will be personally impacted. Another barrier to overcome is the copious amount of communication options available to the public. Local television stations, The Weather Channel, local NWS offices, telephone alerts, local EMsponsored services, weather bloggers, and other social media sources, each with their own graphics and color schemes, risk and outlook categories, and opinions regarding the tornado threat, can lead to inconsistent messaging and public confusion. Uncertainties in the convective mode and environmental ingredients of the tornado were also repeatedly mentioned as a challenge in warning communication. Despite the risk communication barriers, most professionals view the public as aware of the secondary severe weather season in the cold months. The public is also viewed by the professionals as vulnerable to tornado impacts in general, due to the local topography, poverty, lack of education, prevalence of manufactured homes, and a propensity for nighttime tornadoes, although most professionals do not perceive this vulnerability to be increasing over time.

\section{b. Limitations}

Both the methodology and sample size of the survey analysis pose limitations to this study. First, by only sampling professionals, the perceptions of challenges in risk communication and vulnerability are limited to the professional frame of reference, which may or may not be an accurate representation of reality. Data from the public regarding how it receives tornado risk information, as well as its personal beliefs of vulnerability, are necessary to affirm or refute the results. Some professionals may have also been tempted by social desirability (Phillips and Clancy 1972), potentially embellishing their responses so as not to appear ignorant of cold-season tornado risk or ashamed of their performance. Next, only 17 professionals completed the entire survey throughout the four cases, with only one of those being from the EM sector. Despite the relatively low sample size, many of the professionals offered lengthy and thoughtful responses. While more participation could have bolstered the findings and creation of the conceptual model, there was relative consistency among NWS and broadcast meteorologists in their feedback and perceptions for a specific case, as well as among the four cases (this despite only one instance of multiple responses from the same office or station across the four cases). The lack of EM response is unfortunate yet understandable, given the heightened workload and job responsibilities for EMs, particularly surrounding a severe weather event. In addition, many counties in which the cold-season tornadoes of 2016/17 occurred were small and/or rural, with only a few EM personnel responsible for a wide suite of county services.

Another limitation of the study is the subjectivity in the interpretation of survey questions. For example, NWS1.1 confessed, "I don't know enough about the definition of vulnerability to understand how all those factors come together." Terms such as "vulnerability," "preparedness," and "resiliency" are known to be amorphous and carry a variety of interpretations (Alwang et al. 2001), so it is possible that professionals may have had different definitions in mind when answering these survey questions. 


\section{c. Action steps: Implementation and future work}

The final open-ended survey question asked professionals to suggest areas of improvement in communicating cold-season tornado risk among the meteorological and emergency management communities as a whole. A variety of helpful thoughts were offered, mostly related to the challenges discussed above. Public education, which involves teaching about the reality of cold-season tornado risk, how to obtain and respond to tornado warnings, and tornado ingredients, was a common theme. TV1.2 called for improved "education and helping people who need it most," and NWS4.2 suggested cold-season tornado education for elementary school students that focuses on "letting them know it could happen, what to do, and not to panic." One pathway toward greater education is through outreach events, which a couple professionals mentioned either happen in their office or would be beneficial to begin. Arguably, just as important as educating the public is educating the professionals themselves. This can be achieved through building connections among sectors within and outside of the meteorological community. As NWS1.1 aptly wrote, "[we must] continue to build better partnerships with the media" and "work more with social scientists because we don't know this stuff as well as they do." This is also a key recommendation in the recent report "Integrating Social and Behavioral Sciences within the Weather Enterprise," released by the National Academies of Sciences Engineering and Medicine (2018). Focused discussions with social scientists about the latest findings, and formal training of professionals in social science practices, specifically related to warning communication, is a must. Given the issue of inconsistent tornado warning and risk messaging, working to consolidate graphics and threatranking systems into a consistent package used throughout WFOs and television media is warranted. Testing this "less is more" approach for specific tornado events, whether in the cold season or other times of the year, would reveal any difference in public response. Other ideas for improvement expressed by professionals included training on social media platforms, continued refinements in modeling of severe convection, and research geared toward improving "accuracy in forecasting both the mode (linear or cellular) and timing (onset and end) of convection" (NWS1.4).

As mentioned above, future work that solicits the public perception would be of great worth. Perhaps NWS1.1 put it best by saying that professionals must "get a better understanding of how the public receives (or doesn't) our preevent messages. We've had a lot of discussion inside the office about how to create graphics/briefings/etc. for our social media accounts—but it's a meteorologist echo chamber. True answers have to come from the customers." Interviewing the public can validate the opinions shared by experts regarding the same extreme weather phenomenon (Morss et al. 2015; Lazrus et al. 2016), but can also reveal that professionals may hold a faulty view of how the public receives warnings (Demuth et al. 2017, manuscript submitted to Wea. Climate Soc.). Studies have also shown that relationships with professionals and communication of uncertainty can hold more weight in one's eyes than his or her knowledge of the science or the forecast accuracy (Sherman-Morris 2005; Wall et al. 2017). Developing a survey of residents in areas impacted by particular coldseason tornadoes would therefore be valuable in comparing the perceptions of vulnerability and communication barriers held by the experts with perceptions of those to whom their warnings and messages are being received. It would also be intriguing to assess how aware the public is of the increase in cold-season tornado frequency, as compared to professionals. Further, it would be helpful to know from which media sources the public gleans tornado warning information in general, and whether the public is more prone to respond to a threat simply based on environmental cues they can see or sense. Without gauging the public perspective, one is left to conjecture whether inactivity is a result of apathy or of an uncontrollable factor, such as a power outage. That said, capturing the professional perceptions, as accomplished in this paper, is quite revealing in itself and provides the basis for the helpful conceptual model presented. Another question derived from this study that is worthy of future work is whether differences in perception exist between urban and rural settings, from both professional and public perspectives. The results presented here shed new and focused light on the tornado risk and warning dissemination process, emphasizing the relatively underresearched yet important class of cold-season tornadoes. Application to the broader realm of tornado risk communication in general, as precipitated by this study, can help achieve the goal of reaching more people in the most effective ways in order to mitigate societal impacts and reduce human casualty from tornado events.

Acknowledgments. This material is based upon work supported by the National Science Foundation Graduate Research Fellowship Program under Grant DGE1321845 and NOAA Grants NA15OAR4590233 and NA16OAR4590215. Any opinions, findings, and conclusions or recommendations expressed in this material are those of the author(s) and do not necessarily reflect the views of the National Science Foundation. The authors wish to thank Julie Demuth and Jen Henderson from NCAR, as well as Craig Trumbo from CSU, for their support and help with qualitative and content analysis methods. Also, the authors appreciate the two anonymous reviewers for their helpful suggestions and comments toward improving the original manuscript. 


\section{REFERENCES}

Agee, E. M., and S. J. Childs, 2014: Adjustments in tornado counts, F-scale intensity, and path width for assessing significant tornado destruction. J. Appl. Meteor. Climatol., 53, 1494-1505, https://doi.org/10.1175/JAMC-D-13-0235.1.

Allen, J. T., M. K. Tippett, and A. H. Sobel, 2015: Influence of the El Niño/Southern Oscillation on tornado and hail frequency in the United States. Nat. Geosci., 8, 278-283, https://doi.org/ 10.1038/ngeo2385.

Alwang, J., P. B. Siegel, and S. L. Jorgensen, 2001: Vulnerability: A view from different disciplines. World Bank Social Protection Discussion Paper 0115, 46 pp.

Anderson, C. J., C. K. Wikle, Q. Zhou, and J. A. Royle, 2007: Population influences on tornado reports in the United States. Wea. Forecasting, 22, 571-579, https://doi.org/10.1175/ WAF997.1.

Ashley, W. S., 2007: Spatial and temporal analysis of tornado fatalities in the United States: 1880-2005. Wea. Forecasting, 22, 1214-1228, https://doi.org/10.1175/2007WAF2007004.1.

— namic ingredients of risk and exposure are changing the tornado disaster landscape. Bull. Amer. Meteor. Soc., 97, 767786, https://doi.org/10.1175/BAMS-D-15-00150.1.

- A. J. Krmenec, and R. Schwantes, 2008: Vulnerability due to nocturnal tornadoes. Wea. Forecasting, 23, 795-807, https:// doi.org/10.1175/2008WAF2222132.1.

— - S. Strader, T. Rosencrants, and A. J. Krmenec, 2014: Spatiotemporal changes in tornado hazard exposure: The case of the expanding bull's-eye effect in Chicago, Illinois. Wea. Climate Soc., 6, 175-193, https://doi.org/10.1175/WCAS-D-13-00047.1.

Basher, R., 2006: Global early warning systems for natural hazards: Systematic and people-centred. Philos. Trans. Roy. Soc. London, 364, 2167-2182, https://doi.org/10.1098/rsta.2006.1819.

Bergstrand, K., B. Mayer, B. Brumback, and Y. Zhang, 2015: Assessing the relationship between social vulnerability and community resilience to hazards. Soc. Indic. Res., 122, 391409, https://doi.org/10.1007/s11205-014-0698-3.

Bertaux, D., 1981: From the life-history approach to the transformation of sociological practice. Biography and Society: The Life History Approach in the Social Sciences, D. Bertaux, Ed., Sage, 29-45.

Brotzge, J., and W. Donner, 2013: The tornado warning process: A review of current research, challenges, and opportunities. Bull. Amer. Meteor. Soc., 94, 1715-1733, https://doi.org/ 10.1175/BAMS-D-12-00147.1.

Childs, S. J., R. S. Schumacher, and J. T. Allen, 2018: Cold-season tornadoes: Climatological and meteorological insights. Wea. Forecasting, https://doi.org/10.1175/WAF-D-17-0120.1, in press.

Cook, A. R., and J. Schaefer, 2008: The relation of El NiñoSouthern Oscillation (ENSO) to winter tornado outbreaks. Mon. Wea. Rev., 136, 3121-3137, https://doi.org/10.1175/ 2007MWR2171.1.

Cutter, S. L., B. J. Boruff, and W. L. Shirley, 2003: Social vulnerability to environmental hazards. Soc. Sci. Quart., 84, 242-261, https://doi.org/10.1111/1540-6237.8402002.

Davies, J. M., and A. Fischer, 2009: Environmental characteristics associated with nighttime tornadoes. Electron. J. Operational Meteor., 10, 2009-EJ3, http://nwafiles.nwas.org/ej/pdf/2009-EJ3.pdf.

Dewitt, B., B. Fischhoff, A. Davis, and S. B. Broomell, 2015: Environmental risk perception from visual clues: The psychophysics of tornado risk perception. Environ. Res. Lett., 10, 124009, https://doi.org/10.1088/1748-9326/10/12/124009.
Donner, W., and H. Rodríguez, 2008: Population composition, migration and inequality: The influence of demographic changes on disaster risk and vulnerability. Soc. Forces, 87, 1089-1114, https://doi.org/10.1353/sof.0.0141.

Doswell, C. A., III, A. R. Moller, and H. E. Brooks, 1999: Storm spotting and public awareness since the first tornado forecasts of 1948. Wea. Forecasting, 14, 544-557, https://doi.org/10.1175/ 1520-0434(1999)014<0544:SSAPAS >2.0.CO;2.

Emrich, C. T., and S. L. Cutter, 2011: Social vulnerability to climatesensitive hazards in the southern United States. Wea. Climate Soc., 3, 193-208, https://doi.org/10.1175/2011WCAS1092.1.

Fike, P. C., 1993: A climatology of nocturnal severe local storms outbreaks. Preprints, 17th Conf. on Severe Local Storms, St. Louis, MO, Amer. Meteor. Soc., 10-14.

Fischhoff, B., and J. Kadvany, 2011: Risk: A Very Short Introduction. Oxford University Press, $184 \mathrm{pp}$.

— Proc. Natl. Acad. Sci. USA, 111, 13 664-13 671, https://doi.org/ 10.1073/pnas.1317504111.

Hersher, R., 2016: Much of the Southeast U.S. is grappling with drought. NPR, accessed 5 July 2017, http://www.npr.org/sections/thetwoway/2016/11/10/501568892/much-of-the-southeast-u-s-is-grapplingwith-drought.

Hogan Carr, R., B. Montz, K. Maxfield, S. Hoekstra, K. Semmens, and E. Goldman, 2016: Effectively communicating risk and uncertainty to the public: Assessing the National Weather Service's flood forecast and warning tools. Bull. Amer. Meteor. Soc., 97, 1649-1665, https://doi.org/10.1175/BAMS-D-14-00248.1.

Horton, D., and R. Wohl, 1956: Mass communication and para-social interaction: Observations on intimacy at a distance. Psychiatry, 19, 215-229, https://doi.org/10.1080/00332747.1956.11023049.

Lazrus, H., R. E. Morss, J. L. Demuth, J. K. Lazo, and A. Bostrom, 2016: "Know what to do if you encounter a flash flood": Mental models analysis for improving flash flood risk communication and public decision making. Risk Anal., 36, 411427, https://doi.org/10.1111/risa.12480.

League, C. E., W. Díaz, B. Philips, E. J. Bass, K. Kloesel, E. Gruntfest, and A. Gessner, 2010: Emergency manager decision-making and tornado warning communication. Meteor. Appl., 17, 163-172, https://doi.org/10.1002/met.201.

Livingston, I., 2012: The Mississippi Valley outbreak of 1971 and February's only F5 tornado. U.S. Tornadoes, http:// www.ustornadoes.com/2012/02/21/the-mississippi-valleyoutbreak-of-1971-and-februarys-only-f5-tornado/.

Mileti, D. S., and P. W. O’Brien, 1992: Warnings during disaster: Normalizing communicated risk. Soc. Probl., 39, 40-57.

Morrow, B. H., and J. K. Lazo, 2016: Effective tropical cyclone forecast and warning communication: Recent social science advances. Trop. Cyclone Res. Rev., 4, 38-48, https://doi.org/ 10.6057/2015TCRR01.05.

Morss, R. E., and M. H. Hayden, 2010: Storm surge and "certain death": Interviews with Texas coastal residents following Hurricane Ike. Wea. Climate Soc., 2, 174-189, https://doi.org/ 10.1175/2010WCAS1041.1.

, J. L. Demuth, A. Bostrom, J. K. Lazo, and H. Lazrus, 2015: Flash flood risks and warning decisions: A mental models study of forecasters, public officials, and media broadcasters in Boulder, Colorado. Risk Anal., 35, 2009-2028, https://doi.org/10.1111/risa.12403.

— , K. J. Mulder, J. K. Lazo, and J. L. Demuth, 2016: How do people perceive, understand, and anticipate responding to flash flood risks and warnings? Results from a public survey in Boulder, Colorado, USA. J. Hydrol., 541, 649-664, https:// doi.org/10.1016/j.jhydrol.2015.11.047. 
Nagele, D. E., and J. E. Trainor, 2012: Geographic specificity, tornadoes, and protective action. Wea. Climate Soc., 4, 145155, https://doi.org/10.1175/WCAS-D-11-00047.1.

National Academies of Sciences, Engineering, and Medicine, 2018: Integrating Social and Behavioral Sciences within the Weather Enterprise. The National Academies Press, 198 pp., https://doi.org/10.17226/24865.

NCEI, 2017a: Historical records and trends. NOAA, accessed 18 April 2017, https://www.ncdc.noaa.gov/climate-information/ extreme-events/us-tornado-climatology/trends.

_ 2017b: State of the Climate: Tornadoes for January 2017. NOAA, accessed 18 April 2017, https://www.ncdc.noaa.gov/ sotc/tornadoes/201701.

NOAA, 2009: Service assessment: Super Tuesday tornado outbreak of February 5-6, 2008. NOAA Tech. Rep., 48 pp., https://www. weather.gov/media/publications/assessments/super_tuesday.pdf.

_ 2016: Risk communication and behavior: Best practices and research findings. NOAA Tech. Rep., 66 pp., http://www. performance.noaa.gov/wp-content/uploads/Risk-Communicationand-Behavior-Best-Practices-and-Research-Findings-July-2016.pdf.

Paul, B. K., L. Emerson, V. T. Brock, and S. Csiki, 2003: Public response to tornado warnings: A comparative study of the May 4, 2003, tornadoes in Kansas, Missouri, and Tennessee. Natural Hazards Research and Applications Information Center, University of Colorado, Boulder, Quick Response Research Rep. 165, 27 pp.

_ M. Stimers, and M. Caldas, 2015: Predictors of compliance with tornado warnings issued in Joplin, Missouri, in 2011. Disasters, 39, 108-124, https://doi.org/10.1111/disa.12087.

Phillips, D. L., and K. J. Clancy, 1972: Some effects of "social desirability" in survey studies. Amer. J. Sociol., 77, 921-940, https://doi.org/10.1086/225231.

Reynolds, B., and M. Seeger, 2005: Crisis and emergency risk communication as an integrative model. J. Health Commun., 10, 43-55, https://doi.org/10.1080/10810730590904571.

Schramm, H., 2008: Parasocial interactions and relationships. The International Encyclopedia of Communication, Blackwell, 3501.

—, and T. Hartmann, 2008: The PSI-Process Scales. A new measure to assess the intensity and breadth of parasocial processes. Communications, 33, 385-401, https://doi.org/ 10.1515/COMM.2008.025.

Sherburn, K. D., M. D. Parker, J. R. King, and G. M. Lackmann, 2016: Composite environments of severe and nonsevere high-shear,
low-CAPE convective events. Wea. Forecasting, 31, 1899-1927, https://doi.org/10.1175/WAF-D-16-0086.1.

Sherman-Morris, K., 2005: Tornadoes, television and trust-A closer look at the influence of the local weathercaster during severe weather. Global Environ. Change Part B: Environ. Hazards, 6, 201-210, https://doi.org/10.1016/ j.hazards.2006.10.002.

Simmons, K. M., and D. Sutter, 2007: The Groundhog Day Florida tornadoes: A case study of high-vulnerability tornadoes. Natural Hazards Research and Applications Information Center, University of Colorado, Boulder, Quick Response Research Rep. 193, 10 pp.

— and - 2008: Tornado warnings, lead times, and tornado casualties: An empirical investigation. Wea. Forecasting, 23, 246-258, https://doi.org/10.1175/2007WAF2006027.1.

Sims, J. H., and D. D. Baumann, 1972: The tornado threat: Coping styles of the north and south. Science, 176, 1386-1392, https:// doi.org/10.1126/science.176.4042.1386.

Sorensen, J. H., 2000: Hazard warning systems: Review of 20 years of progress. Nat. Hazards Rev., 1, 119, https://doi.org/10.1061/ (ASCE)1527-6988(2000)1:2(119).

SPC, 2017: NOAA's NWS Storm Prediction Center Forecast Tools. NOAA, accessed 28 November 2017, http://www.spc. noaa.gov/climo/online/monthly/newm.html.

Strader, S. M., W. S. Ashley, T. J. Pingel, and A. J. Krmenec, 2017: Projected 21st century changes in tornado exposure, risk, and disaster potential. Climatic Change, 141, 301-313, https://doi.org/10.1007/s10584-017-1905-4.

Sutter, D., and M. Poitras, 2010: Do people respond to low probability risks? Evidence from tornado risk and manufactured homes. J. Risk Uncertain., 40, 181-196, https://doi.org/10.1007/ s11166-010-9087-8.

Trumbo, C., 2013: Communicating the significance of risk. Communication and Engagement with Science: Issues and Dilemmas, J. K. Gilbert and S. M. Stocklmayer, Eds., Routledge, 91-109.

Wall, T. U., T. J. Brown, and N. J. Nauslar, 2017: Spot weather forecasts: Improving utilization, communication, and perceptions of accuracy in sophisticated user groups. Wea. Climate Soc., 9, 215-226, https://doi.org/10.1175/WCAS-D-15-0055.1.

Weber, R. P., 1990: Basic Content Analysis. Sage, 96 pp.

Zhang, F., and Coauthors, 2007: An in-person survey investigating public perceptions of and responses to Hurricane Rita forecasts along the Texas coast. Wea. Forecasting, 22, 1177-1190, https://doi.org/10.1175/2007WAF2006118.1. 